Joan Pujol

Els poemes de Lepant.

A cura d'Eulàlia Miralles i Pep Valsalobre.

Barcelona, Editorial Barcino, 2019, 192p.

ISBN 978-84-7226-841-8

\title{
Lara Vilà
}

Universitat de Girona

lara.vila@udg.edu

Tras diversos años de trabajo ha visto la luz la edición más reciente del que puede que sea el primer poema épico sobre Lepanto publicado en la Península ibérica, La singular y admirable victoria que per la gracia de NSD obtingue el Serenissim Senyor don Juan Daustria de la potentissima armada Turquesca. La obra apareció en un ejemplar en octavo preparado en las barcelonesas prensas de Pere Malo en 1573 y circuló también en un manuscrito posterior, actualmente custodiado en la Biblioteca Mazarine de París. Obra de Joan Pujol, poeta catalán nacido en Mataró a mediados del siglo XvI, el Lepant es una breve epopeya escrita en su mayor parte en cobles decasil.làbiques y dividida en tres cantos, cuya singularidad radica en el hecho de que constituye el centro de un pequeño ciclo dedicado a celebrar la victoria cristiana. Este, como indican los editores, debe considerarse a su vez el núcleo de la obra pujoliana, razón por la que el presente volumen, con el pertinente título de Els poemes de Lepant, ofrece la totalidad de las composiciones dedicadas a la materia lepantina siguiendo la disposición del impreso barcelonés: las dos dedicatorias a Jeroni de Pinós, el Lepant, los dísticos latinos de Lluís Joan Vileta acompañados de la traducción y glosa de Pujol y, por último, el conjunto de seis poemas laudatorios de los mismos Pinós y Pujol, y uno de Francesc Comte, que sirven de cierre al conjunto. La edición de Miralles y Valsalobre constituye pues una meritoria aportación al estudio de la obra pujoliana en clave peninsular y europea, que completa y corrige, al gravitar en torno a la centralidad del ciclo lepantino, la edición preparada por Karl-Heinz Anton en 1970.

Preceden a la edición de los poemas lepantinos una "Presentación" y una "Introducción". Ofrece la primera las directrices que sustentan el reconocimiento de la obra pujoliana tanto en el ámbito literario catalán, por lo innovador 
de su poesía, como en el hispánico y el europeo, por el carácter inaugural y la naturaleza contrarreformista de su poema épico. En una buena presentación del problema, los editores proponen una lectura que quiere vincular la obra pujoliana con los principales episodios históricos y culturales de la Europa de la segunda mitad del Quinientos. A partir de estas premisas generales, el estudio introductorio plantea en su primer apartado ("Lautor i el seu cercle") un análisis de la figura y la obra de Pujol que reconstruye, a partir de los escasos datos que manejamos de su biografía y de los testimonio del impreso de 1573 y del manuscrito parisiense, el círculo frecuentado por el autor, clave para comprender las bases intelectuales de la escritura del ciclo lepantino y que le confieren un sesgo catalán y moral muy acentuado. Así pues, este apartado se centra en la identificación de sus amistades, entre las que se cuentan el historiador Francesc Comte, Ildefons Coloma, que fue obispo de Barcelona, y el canónigo y músico Pere Alberch Vila. En el centro de este grupo destacan la figura del lulista Lluís Joan Vileta y el noble Jeroni de Pinós, dedicatario y puede que promotor de $L a$ singular y admirable victoria, en cuyo entorno debían de reunirse todos ellos. En Vileta puede que viera Pujol un mentor, y no es descartable, como sostienen Miralles y Valsalobre, que sus dísticos latinos sobre la victoria lepantina inspiraran la composición de los versos del Lepant. Esta ascedencia intelectual podría ampliarse a los poemas lepantinos de otros dos posibles miembros de este grupo, Antonio Lo Frasso y Jeroni Costiol, lo que certificaría las relaciones dentro de este núcleo barcelonés y el innegable interés de estos escritores por la materia.

El segundo apartado ("L'obra poética") reivindica la importancia de la obra pujoliana en el ámbito de la literatura catalana del Renacimiento. A Pujol y Pere Serafí se deben los dos únicos cancioneros en catalán publicados durante la segunda mitad de siglo. Lo que distingue la poesía de Pujol, que está formada, si seguimos el orden del manuscrito de París, por tres grandes grupos -el ciclo lepantino, los textos ausiasmarquistas en catalán y un conjunto heterogéneo de obras de naturaleza circunstancial escritas en catalán y castellano- es su adopción de las fórmulas de la Contrarreforma y lo que los editores denominan un "replegament cultural" (p. 30), que busca definir una tradición propia y que se percibe especialmente en los dos primeros. Del ciclo lepantino destaca la centralidad de una lectura en clave católica, que suma el elogio de diversas nisagas catalanas que contribuyeron a la victoria cristiana, mientras que los textos relacionados con la obra de March siguen una senda moral y contrarreformista, inspirada de cerca por Vileta, que busca deliberadamente alejarse de la lectura renacentista de matriz castellana. El resto de la producción poética pujoliana, obra religiosa en su mayor parte, aguarda en el futuro un estudio más detenido.

Los dos siguientes apartados conciernen al estudio del ciclo lepantino. El primero ("Lepant en la tradició literària") relaciona la obra pujoliana con los testimonios, también muy tempranos, de Lo Frasso y Costiol. Este interesante conjunto de obras lepantinas, publicadas en Barcelona entre 1571 y 1573, parece responder a la influencia viletiana, lo que permitiría, pese a sus divergencias, 
considerar la existencia de un grupo intelectual que tuvo en el triunfo cristiano uno de sus intereses más conspicuos. La estructura del ciclo lepantino de Pujol y el hecho de que el conjunto pueda considerarse el núcleo de su obra, al que se habrían añadido en una segunda fase las demás composiciones, podrían certificar esta asunción. En consecuencia, el cuarto y último apartado ("Els poemes de Lepant") se ocupa del análisis de las piezas que componen el ciclo, dispuestas en el impreso de acuerdo con una ordenación muy clara: las dos dedicatorias a Jeroni de Pinós conforman una suerte de proemio a las dos piezas centrales -el Lepant, seguido de los dísticos de Vileta y la versión catalana y glosa de Pujol- que cierran de forma conveniente los poemas laudatorios. Particular interés suscita a los editores la relación del poema pujoliano con los dísticos latinos de Vileta, con el que detectan notables coincidencias que permitirían considerar las glosas, quizá, como una primera fase de escritura de la epopeya. Pero lo más destacado es sin duda la lectura del poema, que consideran, esencialmente, un ejemplo de "èpica cristiana contrareformista" (p. 52), interesado en ensalzar el triunfo de la unidad católica a través de la unidad argumental de la epopeya. Esta puede enlazarse, tras la lectura propuesta por Sergio Zatti, con valores de orden literario como la ortodoxia neoaristotélica frente a la variedad del romanzo, y de orden político, en el que destaca el elogio de la monarquía filipina como poder político centralizado y principal artífice de la victoria. No obstante, sostienen los editores que el poema incorpora al marco general de la alabanza hispánica la de las dinastías catalanas partícipes y responsables también del triunfo, con lo que consideran que se produce en el caso de Pujol una desviación "de la línea de l'èpica filipina més habitual, perquè per a ell l'exaltació de la ideologia imperial hispànica no és, ni de bon tros, l'objetiu a assolir" (p. 53). El catalanismo pujoliano se sostendría también en el hecho de que el poema no recrea gestas anteriores de la dinastía austríaca, lo que constituye a juicio de Miralles y Valsalobre una singularidad que merece tenerse en cuenta. Esta perspectiva reviste, de hecho, gran interés cuando se amplía el marco comparativo, pues reencontramos estrategias parecidas en otros poemas contemporáneos sobre la materia. Este es el caso, por ejemplo, de la epopeya sobre Lepanto que Juan Latino publicó también en 1573, en el que transitamos por la misma senda de la unidad argumental y católica, o de la reivindicación portuguesa que leemos en la Felicísima victoria, concluida en 1575 e impresa en 1578 por Jerónimo Corte-Real. En este sentido, y más allá de consideraciones modélicas que no podemos confirmar, la lectura del Lepant realizada por Miralles y Valsalobre resulta pertinente ya que permite vincular el poema pujoliano con otros títulos de la tradición ibérica, a la vez que enfatiza la riqueza semántica de la épica peninsular al plantear la existencia de diferentes estratos interpretativos, que amplían e incluso pueden llegar a problematizar en algunos casos la lectura imperial aparentemente hegemónica. Por ello, no podemos más que celebrar esta esmerada edición de la obra de Joan Pujol, que a la vez que resitúa la centralidad del conjunto lepantino permite ahondar en la escritura épica ibérica del Quinientos. 
